\title{
IEDITORIAL
}

\section{Inequality between men and women: a very old problem, not only in politics but also in chronic coronary artery disease}

\author{
Roberto Ferrari \\ 1 Maria Cecilia Hospital, GVM Care \& Research, Cotignola, Italy \\ 2 Centro Cardiologico Universitario di Ferrara, University of Ferrara, Ferrara, Italy
}

\section{RELATED ARTICLE} by Duda-Pyszny et al, see p. 393
Correspondence to: Prof. Roberto Ferrari, MD PhD, Centro Cardiologico Universitario di Ferrara, University of Ferrara,

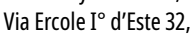
44121 Ferrara, Italy, phone: +390532293707, email: fri@unife.it Received: February 24, 2021. Accepted: February 25, 2021. Published online: April 23, 2021. Kardiol Pol. 2021; 79 (4): 376-377 doi:10.33963/KP.15949 Copyright by the Author(s), 2021
In Italy, my country, we have experienced a recent governmental change. Professor Mario Draghi, the previous president of the European Central Bank and Bank of Italy, is the new Prime Minister. The nation has enthusiastically hailed him, so has the international press.

Political parties, which are arguing all the time with the government and among themselves, remained silent, recognizing that he is, probably, the best figure to run Italy. But... he made a critical mistake that has allowed (some) complaints from political parties: inequality between men and women in the composition of the Council of Ministers (15 men vs 8 women).

Inequality between the 2 genders is not new and not confined to politics. It is common in several various areas including healthcare and particularly evident in the case of acute and chronic coronary syndromes. There are several reasons for this. Men and women are not the same and one would say "Vive la difference." La difference between genders occurs also for risk factors, coronary artery plaque development, atherothrombosis, vascular injuries or coagulation, all determinants of coronary syndromes. This is driven mainly by 2 discrete hormones-estrogens and testosterone. Although the effects are highly complex and only partially elucidated, in general, it seems that estrogens exert a more protective effect on the coronary artery endothelium and have a less prothrombotic effect than testosterone. ${ }^{1}$ This has led to the popular misconception, across Europe and the rest of the world, that cardiovascular disease (CVD) is a male disease. In fact, in Europe, CVD is the main cause of death in both men and women, killing even a higher percentage of women than men and doing it more effectively than all cancers combined. Yet, according to public awareness surveys, women seem to think that they are at higher risk of cancer, especially breast cancer.

The underestimation of the impact of CVD in women is however not confined to the public. Medical professionals equally need to improve the screening, diagnosis, treatment, and follow-up of women with CVD and its underlying risk factors. Since women's symptoms and disease progression trends differ from those of men, primary care physicians and cardiologists are all too frequently underdiagnosing and undertreating women, being insufficiently familiar with their less "traditional" presentation profiles.

Such earlier thinking that women are less affected by coronary syndromes is changing, and several contemporary reports indicate that the so-called gender gap is closed and, actually, even reversed..$^{2-5}$ In this issue of Kardiologia Polska (Kardiol Pol, Polish Heart Journal), Duda-Pyszny et $\mathrm{al}^{6}$ provide evidence that, in Poland at least, some gender gaps do still exist. The Prospective Registry of Stable Angina Management and Treatment (PRESAGE), in fact, followed up 11201 patients subjected to coronary angiography for 10 years and showed that the composite endpoint including death was more frequently reached in men than in women, although women were older than men, had more risk factors (hypertension and diabetes), and men received more percutaneous coronary interventions and coronary artery bypasses than women. ${ }^{6}$ However, in multivariate analysis, sex was 
no longer an independent predictor of the endpoint. The finding that sex is not an independent predictor of mortality in the Polish population is in line with other large international analyses of contemporary patients with chronic coronary syndromes $^{6,7}$ and raises the question why death and other components of the endpoint, that is, myocardial infarction, unstable angina, revascularization, and stroke, were more frequent in men than in women despite the fact that women were older than men. There are several reasons for this. The gender-age gap in developing chronic coronary syndromes is usually attributed to the protective role of estrogens, but it was also suggested that women, after menopause, are catching up with their male counterparts. ${ }^{7,8}$ It may be due to the well-known gender bias in diagnosis and access to interventional procedures but also due to different underlying pathomechanisms. ${ }^{9}$ Female coronary pathophysiology is characterized by less epicardial stenosis and greater microvascular dysfunction compared with men, which accounts for the relative lower rate of revascularization. ${ }^{7}$ Such pathophysiological differences are linked to atypical symptoms, delay in seeking care, and underutilization of evidence-based therapies in women. Our Polish colleagues, however, should be complimented on their work, as there were no major differences in medical treatment, either preventive or symptomatic, between the 2 study groups. Other factors cannot be underestimated, such as socioeconomic status, psychosocial stress and, obviously, family and maternal history as well as genetics. ${ }^{8}$

The next question is: what will the future hold? I cannot predict whether gender inequalities among Professor Draghi's ministers will be good or bad. Let's be optimistic! As for Poland, apart from complimenting Polish physicians on the results and the rather low mortality rates, regardless of sex, I would say that the findings are not totally new: even in the Egyptian mummies, it was found that men suffered from epicardial coronary artery disease more often than women. The reason, at that time, was simple: more food (probably fat!) for men! Probably, this is no longer the case today.

\section{ARTICLE INFORMATION}

DISCLAIMER The opinions expressed by the author(s) are not necessarily those of the journal editors, Polish Cardiac Society, or publisher.

CONFLICT OF INTEREST RF has received research grants and personal fees from Novartis and Servier as well as personal fees from Merck Serono, Boehringer Ingelheim, Sunpharma, Lupin, Doc Generici, Pfizer, and Spa Prodotti Antibiotici. He is a director of Art Research and Science S.r.I (A.R.S.1).

OPEN ACCESS This is an Open Access article distributed under the terms of the Creative Commons Attribution-NonCommercial-NoDerivatives 4.0 International License (CC BY-NC-ND 4.0), allowing third parties to download articles and share them with others, provided the original work is properly cited not changed in any way, distributed under the same license, and used for noncommercial purposes only. For commercial use, please contact the journal office at kardiologiapolska@ptkardio.pl.

HOW TO CITE Ferrari R. Inequality between men and women: a very old problem, not only in politics but also in chronic coronary artery disease. Kardiol Pol. 2021; 79: 376-377. doi:10.33963/KP.15949

\section{REFERENCES}

1 Haider A, Bengs S, Luu J, et al. Sex and gender in cardiovascular medicine: presentation and outcomes of acute coronary syndrome. Eur Heart J. 2020; 41: 1328-1336.

2 Crilly M, Bundred $\mathrm{P}$, Hu $\mathrm{X}$, et al. Gender differences in the clinical management of patients with angina pectoris: a cross-sectional survey in primary care. BMC Health Serv Res. 2007; 7: 142.

3 Hochman JS, Tamis JE, Thompson TD, et al. Sex, clinical presentation, and outcome in patients with acute coronary syndromes. Global Use of Strategies to Open Occluded Coronary Arteries in Acute Coronary Syndromes IIb Investigators. N Engl J Med. 1999; 341: 226-232.

4 Alfredsson J, Stenestrand U, Wallentin L, Swahn E. Gender differences in management and outcome in non-ST-elevation acute coronary syndrome. Heart. 2007; 93: 1357-1362.

5 Ferrari R, Abergel H, Ford I, et al. Gender and age related differences in clinical presentation and management of outpatients with stable coronary artery disease. Int J Cardiol. 2013; 167: 2938-2943.

6 Duda-Pyszny D, Trzeciak P, Desperak P, et al. Comparison of clinical characteristics, in-hospital course, and 12-month prognosis in women and men with chronic coronary syndromes. Kardiol Pol. 2021; 79: 393-400.

7 Steg PG, Greenlaw N, Tardif JC, et al. Women and men with stable coronary artery disease have similar clinical outcomes: insights from the international prospective CLARIFY registry. Eur Heart J. 2012; 33: 2831-2840.

8 Gabet A, Danchin N, Juilliere Y, Olié V. Acute coronary syndrome in women rising hospitalization in middle-aged French women, 2004-14. Eur Heart J. 2017; 38: 1060-1065.

9 Ferrari R, Camici PG, Crea F, et al. A "diamond" approach to personalized treatment of angina. Nat Rev Cardiol. 2018; 15: 120-132. 